\title{
Arte y currículum (Disciplina, Interdisciplina y multidisciplina en la licenciatura en Artes)
}

\author{
SOnia VIRAMONTES CABRERA \\ Universidad Autónoma de Zacatecas \\ sonia.viramontes@hotmail.com \\ Javier ACOSTA ESCAREÑO \\ Universidad Autónoma de Zacatecas \\ javierae@hotmail.com
}

\section{Resumen:}

Reflexiones, preguntas y respuestas en torno a la viabilidad del pensamiento complejo en la Licenciatura en Artes de la Universidad Autónoma de Zacatecas.

Palabras clave: Arte; currículum; multidisciplina.

\section{Art and Curriculum.}

\begin{abstract}
:
Reflections, questions and answers to revolve around the feasibility of mindset complex in the Bachelor's degree in Arts of University Autonomous of Zacatecas.
\end{abstract}

Key Words: Art; curriculum; multidiscipline

\section{Referencia normalizada:}

Viramontes Cabrera, S. y Acosta Escareño, J. (2014): Arte y currículum (Disciplina, Interdisciplina y multidisciplina en la licenciatura en Artes). Historia y Comunicación Social. Vol. 19. Núm. Especial Marzo. Págs. 755-762.

Sumario: Introducción. 1. ¿Es viable la creación de una licenciatura en Artes?. 2. ¿Licenciaturas en arte? ¿Licenciatura en Artes. 3. ¿Por qué y cómo la complejidad en un modelo de educación superior en artes? 4. ¿Por qué (no) primero artistas que etcétera? 5. ¿Pueden profesores y alumnos abandonar los compartimentos estancos del arte? 6. ¿Y todavía así queremos libertad? 7. ¿Y si queremos enseñar algo que ya está muerto? 


\section{Introducción}

Esta ponencia surge de ciertos comentarios al margen, a propósito de la recién creada Licenciatura en Artes de la Universidad Autónoma de Zacatecas, que ofrece un enfoque multidisciplinar, general y contextual en su propuesta pedagógica. El proyecto ha sido puesto en marcha en enero de 2011 y todavía no se cuenta con datos e instrumentos suficientes para la evaluación del proyecto, especialmente para determinar que tan acertada es su propuesta pedagógica: digamos entonces que este documento reúne algunas preguntas e intentos de respuestas de orden meramente provisional. Se podrán encontrar en la exposición de este breve auto cuestionario, algunos antecedentes que hacen entendible la estructura curricular de esta nueva oferta educativa.

\section{1. ¿Es viable la creación de una licenciatura en Artes?}

La primera pregunta fue referida a la necesidad de una oferta educativa a nivel superior en las artes, en un medio oprimido como el zacatecano, en una universidad con presupuestos siempre insuficientes, en un área de la actividad económica sin aparente demanda laboral. Lo primero que teníamos era un pequeño núcleo de profesores, provenientes de las áreas de humanidades y educación así como de la coordinación de extensión de la misma universidad, interesados en trabajar en el diseño curricular. De manera simplificada, podemos decir que los profesores del área de Humanidades provenían de una trayectoria relativa a la Teoría del Arte, mientras que los profesores de Extensión se habían formado en los talleres y eran ellos mismos profesores del área de Creación y Difusión. Se contaba ya con un cuerpo de profesores que se encontraban dispersos, pero que reuniendo sus capacidades y formulando adecuadamente una estructura curricular, volverían viable la apertura de una nueva oferta educativa, pues se ajustaba entonces la propuesta a la primera de las dos condiciones que formularon la administración central y el Consejo Universitario:

- a) Que no significara nuevas erogaciones presupuestales.

- b) Que fuera acompañada de la integración del Área de Arte y Cultura de la UAZ, hasta entonces constituida únicamente por el programa de Licenciatura en Música, perteneciente a la misma Unidad Académica.

\section{2. ¿Licenciaturas en arte? ¿Licenciatura en Artes?}

La pregunta que nos hemos formulado fue así mismo el origen del proyecto curricular de la recién creada Licenciatura en Artes de la Universidad Autónoma de Zacatecas. La pregunta era, ¿qué necesitamos y qué es posible realizar, una licenciatura o varias licenciaturas en distintas artes? Esta pregunta fue planteada al principio de 
los trabajos y dividió al equipo en dos grupos, aquellos que deseaban la implementación de licenciaturas por separado, mientras que otro grupo de profesores proponían la implementación de una licenciatura en artes combinadas, con cuatro énfasis diversos - Artes Escénicas, Artes Visuales, Teoría y Enseñanza Artística- pero con ejes comunes y con dispositivos curriculares que descentraran la especialización. El debate se fijó entonces en la disputa entre quienes justificaban la apertura de distintas licenciaturas de acuerdo con el modelo disciplinar, mientras que el otro grupo sostenía la aplicación de un modelo más económico, en el que se pudiera dar una solución que integrara las visiones disciplinar, multidisciplinar e interdisciplinar - siguiendo el nuevo modelo académico de la universidad y también el enfoque complejo siguiendo la crítica de disciplinariedad formulada por Edgar Morin. ${ }^{1}$ La discusión no duró más que dos sesiones, en las que se intercambiaron argumentos que resultaron irreconciliables. El grupo disciplinar abandonó el proyecto, pero no realizó una propuesta alterna.

Y para entonces se había agregado una tarea más a aquella de cómo justificar que los fondos públicos para respaldar la educación e las artes.

\section{3. ¿Por qué y cómo la complejidad en un modelo de educación superior en artes?}

Por complejidad entendimos, con E. Morin, un saber implicado en el contexto y no un saber aislado en sí mismo; pero también un saber no segmentado, siguiendo la crítica del filósofo francés. También como Morin, pensamos que la formulación de un saber no segmentado, no afianzado en la especialización, no debe significar la preparación de todologos del arte. Así que nos pusimos a trabajar en la creación de un centro de estudios en el que se desarrollaran los saberes disciplinarios según las tradiciones pedagógicas establecidas, ámbito homologador —o de los «saberes del bagaje cultural legalizado», como los describe el profesor Humberto Chávez ${ }^{2}$ conjugado con las derivas vitales, fundamentadas en el ámbito de la curiosidad como motor de la creación y el conocimiento, y la formación de trayectorias cruzadas, mixturas artísticas. ${ }^{3}$ Pensábamos que era posible la formación en la especialidad, fomentarla en su rigor; pero apoyados en los conceptos curriculares de flexibilidad y en la polivalencia contenida en el perfil de egreso deseable según el nuevo modelo educativo de la universidad. ${ }^{4}$

1 Para el concepto de complejidad como saber implicado en el contexto y no el conocimiento segmentado, se puede consultar la obra de Edgar Morin, Los siete saberes necesarios para la educación del futuro. México: UNESCO, 1999, p. 38.

2 Chavez Mayol, Humberto, «Complejidad, arte y signo: una metodología interdisciplinaria», en: Interdisciplina. Escuela y arte. Conaculta/Cenart, 2004, p. 160.

3 El valor de la curiosidad ha sido revalorado también por Morin, op. cit. p. 38.

4 Vid. Modelo Académico Universitario, UAZ 2005, p. 30. 
Las primeras objeciones al proyecto fueron precisamente en el sentido de que un modelo como ese formaría todólogos del arte, gente que no conocería nada en profundidad, diletantes con título, por decirlo de manera sumaria. El modelo del conservatorio era el que objetaba de manera más decidida: la formulación del intérprete que cultiva y debe cultivar disciplinadamente su instrumento, el bailarín clásico que debe comenzar desde pequeño y dedicar un alto número de horas al día y a la semana a la práctica del instrumento.

Se argumentó a favor: el saber contextual remite a una seña de identidad para la Licenciatura en Artes, que pudiera ser afín con el entorno regional y con la visión de la educación acuñada en el último foro de reforma de nuestra institución. Hacer de los estudios superiores en arte una visión hacia la generalidad del arte desde las especies del arte - ya que el arte se dice y se hace de distintas maneras - : se insistía, de manera algo machacona, primero artistas que actores, primero artistas que pintores, primero artistas que educadores del arte.

Se produjo una estructura curricular, con un plan de estudios en el que se proponen ejes compartidos con materias obligatorias como: Historia del Arte, Arte y Pensamiento, Arte Cultura y Sociedad, Escritura Creativa, Disciplina Alterna, Taller de Trabajo Conjunto Interdisciplinario. Se pierden horas dedicadas a la profundización de las orientaciones terminales, y se ganan horas para créditos dedicados a las visiones conjuntas, al convivio de las artes y de los estudiantes y los profesores.

\section{4. ¿Por qué (no) primero artistas que etcétera?}

Pintar para crear y no crear para pintar, pero también actuar para crear y no crear para actuar, por ejemplo. El proyecto postula, en sus perfiles de egreso, a un sujeto capaz de crear y de trazar puentes entre las disciplinas: capaz de reconocer y producir el arte en su generalidad a partir de particularidades disciplinares y no disciplinares - no sometidas fatalmente al modelo enciclopédico clasificatorio. Sí, como afirma Rilke, todas las artes enseñan lo mismo, es decir, que otra forma de vida es posible, el perfil de egreso intenta un sujeto que plantee prioritariamente esa potencia de alteridad. Si como dice Beuys, cada hombre es (o debe ser) un artista, el egresado de la Lic. en Artes debería propiciar la transformación de los modos de vida y el modo de vida artístico en su entorno. Así debería ser, y ese es el propósito del arte como educación para la libertad, según la vieja utopía arrojada por Schiller y recogida por Nietzsche o Beuys. Luego de ello, de manera más convencional, el egresado debe saber trazar puentes entre las artes; trabajar en equipos interdisciplinarios con espíritu de colaboración, apertura, tolerancia y respeto; capaz de debatir, enriquecer y fortalecer las ideas de identidad y diversidad; con la habilidad de diseñar, proponer y concretar proyectos alternativos e innovadores que contribuyan a la producción, difusión, estudio y desarrollo de las artes. 
Pero después, como prioridad material, que el egresado sea capaz de crearse un mercado de trabajo. ¿Es ello compatible con esta «ciencia de la libertad»? ¿Se puede vivir de ser libre y de enseñar las disciplinas de la libertad?

\section{5. ¿Pueden profesores y alumnos abandonar los compartimentos estancos del arte?}

De acuerdo con la propuesta pedagógica de la Licenciatura en Artes, "el profesor no debe ser de una materia, debe conocer entonces con detalle las implicaciones de términos como complejidad, generalidad, flexibilidad, especialidad, multi, inter y transdisciplinariedad; todo ello para que pueda ir más allá del mero papel de mentor o instructor, y así pueda convertirse en motivador, asesor y acompañante del alumno. Para ello también se requiere formar al alumno en esa instancia paralela al pensamiento productor de saberes, se trata de acompañarlo en el descubrimiento del pensamiento productor de formas y de visiones del mundo, el pensamiento creador de mundos posibles. De hacer propuestas que incidan en el contexto y en el mundo del arte al mismo tiempo que se convierten en un proyecto de vida. De ahí que resulte fundamental acompañar al alumno-investigador en el desarrollo del pensamiento creativo, cuyo rigor y complejidad son equiparables de pleno derecho con el pensamiento discursivo-científico." 5

Transcurrido un semestre y medio desde la implementación del proyecto, el panorama es difícil. Las convicciones que se observan en las prácticas docentes a nivel primario, medio y medio superior se repiten en el nivel licenciatura. Mi materia es más importante, o dicho de otra manera, necesita más horas, no basta con el número de créditos asignados al programa. Los alumnos inscritos en las diversas salidas terminales estrechan lazos de pertenencia, deseable e indeseable, según el modelo pedagógico, habitualmente consideran "intrusos" en sus talleres o aulas a los alumnos de otras orientaciones. Profesores y alumnos requieren de orientación en el conocimiento del plan de estudios y en el desarrollo de actividades que observan las exigencias disciplinares y el enfoque general. Por un lado tenemos las reuniones de profesores y las sesiones en que se hacen ejercicios de crítica de los trabajos de los alumnos, en los que se muestra apertura e inclusión, por otro lado, se observan actitudes de intolerancia entre grupos de alumnos según la salida terminal.

El instrumento de bitácora, diario académico revisado por el asesor ha facilitado la solución de algunos problemas de rendimiento, así como replantear las estrategias didácticas de los profesores (propiciando el diálogo en la junta de profesores, con buenos resultados de crítica y autocrítica). El acercamiento también ha revelado tendencias de conflicto y relaciones de afinidad entre los integrantes de la comunidad, lo que permite visualizar situaciones de riesgo y desviaciones del enfoque

5 Estructura curricular de la Licenciatura en Artes. Zacatecas: UAZ, 2009, p. 83. 
pedagógico, detectar focos rojos en la convivencia de alumnos iguales respecto de los perfiles generales de egreso; pero diferentes de acuerdo a los perfiles específicos de la orientación.

Tenemos entonces un par de dispositivos, uno que propicia la comprensión de la labor artística más allá de la disciplina, afianzado en materias que enfatizan la reflexión sobre los principios generales del arte y por otro lado, un dispositivo que propicia el trabajo dentro de las disciplinas en diálogo; dispositivos que no operan sobre subjetividades ideales, sino con individuos. Se producen en ambos situaciones de colaboración, pero también de fricción, en general de menosprecio del otro, el que no pertenece a mi disciplina. Educación para la libertad, sí; pero educación también para la tolerancia y la coexistencia, para la disposición al diálogo en una colaboración horizontal. Tales contenidos (tolerancia y respeto) aparecen de manera transversal en varias de las unidades didácticas elaboradas para integrar el plan de estudios, sin embargo emergen ahora como necesidades de urgente atención.

Intercambio, debate, colaboración y aprendizaje: no se dan por añadidura. Para lograrlo, la Licenciatura en Artes requiere de una planta docente que no se limite a la impartición de contenidos y al desarrollo de competencias disciplinares. De ahí que resulte necesaria la implementación de un Programa de Formación de Profesores que esté en consonancia con la propuesta pedagógica.

\section{6. ¿Y todavía así queremos libertad?}

Queremos educación en el arte, por el arte, en el mismo sentido que lo plantea Herbert Read o Friedrich Schiller o Joseph Beuys. Así, como ellos han pensado que la actividad artística es la actividad humana libre por definición, donde el hombre ya no está sometido por la necesidad, sino desprendido, arrojado a lo que él mismo es cuando está sobre puesto al ámbito del horror. Devastación natural o humana, mecanización material y administrativa del mundo. ¿Y contra todo ello un endeble proyecto de licenciatura, en un país sitiado por la necesidad?

Una de las culminaciones de la administración de la vida y de la emergencia del horror nos ha tocado vivirla ahora, cien años después de ese último imperio del hambre y de la muerte que vivieron nuestros abuelos y nuestros bisabuelos, los tiempos de la bola, los tiempos de la necesidad, como ellos los llamaban. Después de ese tiempo, regurgitado, el tiempo del terror sin control, tiempos de la necesidad narcótica.

Nos hemos tomado - ya desde antes de todo esto, desde hace mucho, un bebedizo del adormecimiento, del sopor y del olvido, como la isla de los bebedores de loto de la Odisea. Aquello que hemos olvidado es precisamente lo que nos da el arte, y en un sentido (más) general, su poesía. El regalo del arte al hombre es sencillo y sobrenatural: avizorar otras formas de vida, ver, hacer y vivir de otro modo. Las razones del otro y lo otro de la razón, ambas dadas por el arte y desdeñadas por los administradores de la cultura. Sin embargo, apreciación y creación, que se han visto 
como una división natural, deben ser unidas en esa antigualla llamada ser humano, la persona, el individuo. Por medio de la educación, de la paideia para el arte y desde el arte. Educar para crear es educar para recrear y recrearse, es decir, devenir otro, hacerse otro en el arte, alcanzar los límites de lo que uno es y no es. Educar para crear es potenciar el devenir del otro en uno mismo: hospitalidad para con la dignidad del otro.

Educar para crear es abrir el espacio más allá de la disciplina y la interdisciplina, más allá incluso de la multidisciplina, es agrietar el lugar para el sentimiento, la penumbra, la duda y la vacilación. La única manera como decía Rilke de «escribir un poema que sólo tú puedas escribir». El riesgo es la ley, pero es fascinante como dice Hugo Hiriart. ${ }^{6}$

\section{7. ¿Y si queremos enseñar algo que ya está muerto?}

Esta pregunta, como la anterior, no atañen a este u otro proyecto de educación artística, pero conforman su raíz, su inconsciente pedagógico. ¿No es, eso que aún queremos aprender y enseñar una cosa del pasado? ¿Están condenadas todas las escuelas del arte a ser mera didáctica de los suntuosos archivos de lo que fue, en alguna ocasión, eso que ya no es el arte? Entonces, el significado de la muerte del arte puede tener otro sentido, desvinculado de la crítica del olvido de su supuesta tarea como trabajo formal dedicado a la belleza y a su agotamiento. Muerte del arte en tanto es llevado a un ensimismamiento reactivo. Encerrado en sí mismo, por regla general. Y entre más apartado y distante, mejor: y entre más diálogo con los referentes intraartísticos, mejor. Y entre más poesía para poetas, y entre más pintura para pintores, y entre más arte para artistas, mejor. ¿Y la educación artística? una herramienta para completar el currículum del programa académico común: toca la cuerda, copia la paloma, escribe la rima, mezcla el color. Y hemos encontrado la incapacidad para mencionar lo que tenemos a la mano, el mundo prosaico de la necesidad. Narcosis utópica: narcoutopía.

¿No debe el arte inundar el mundo, sin disiparse en mera estética? No debe la educación formular el contexto en el que arte y mundo puedan contaminarse? ¿No debe el arte otra vez considerar su papel como base de la paideia? El célebre tratado de Herbert Read Educación por el arte comienza con un epígrafe de Bernard Shaw que todavía debemos recordar: "Me limito a llamar la atención sobre el hecho de que las bellas artes son el único maestro, fuera de la tortura." 7

No lo sabemos todavía, estamos esperando que salga nuestra primera generación para ver los resultados de un proyecto que esperamos no esté muerto, hemos empezado a pintar un cuadro y cada pincelada compromete y restringe las posibilidades.

6 Hiriart, Hugo, Los dientes eran el piano, Tusquets, México, 1999, p. 233.

7 Read, Herbert, Educación por el arte. Buenos Aires: Paidós, 1973. 
El asunto es que como en el arte no podemos hacer lo que nos dé la gana, sino lo que corresponde y es coherente con ese planteamiento. De ahí la dificultad.

\section{Bibliografía:}

CHÁVEZ MAYOL, Humberto (2004). Complejidad, arte y signo: una metodología interdisciplinaria. México: CONACULTA/CENART

HIRIART, Hugo (1999). Los dientes eran el piano, México: Tusquets.

MORIN, Edgar (1999). Los siete saberes necesarios para la educación del futuro. México: UNESCO.

READ, Herbert (1973). Educación por el arte. Buenos Aires: Paidós.

8.1 Documentos Universitarios:

Modelo Académico Universitario, UAZ 2005,

Estructura curricular de la Licenciatura en Artes. Zacatecas: UAZ, 2009, p. 83.

8.2 Publicaciones web

MORIN, Edgar, Introducción al pensamiento complejo (fecha de consulta 20 septiembre de 2013) disponible en: "http://www.pensamientocomplejo.com.ar/ docs/files/MorinEdgar_Introduccion-al-pensamiento-complejo_Parte1.pdf 